\title{
]jfis
}

\section{Effectiveness of Neuro-fuzzy Inference System for Predicting Player Character in the Balinese Serious Game Model}

\author{
I Nyoman Putu Suwindra1 ${ }^{1}$, Ketut Gede Darma Putra ${ }^{2}$, Made Sudarma ${ }^{2}$, and \\ Nyoman Putra Sastra ${ }^{2}$ \\ ${ }^{1}$ Faculty of Mathematics and Natural Sciences, Ganesha University of Education, Bali, Indonesia \\ ${ }^{2}$ Faculty of Technology and Engineering, Udayana University, Bali, Indonesia
}

Received: Jan. 2, 2021

Revised : Apr. 11, 2021

Accepted: Jun. 9, 2021

Correspondence to: I Nyoman Putu Suwindra (suwindra@undiksha.ac.id)

@The Korean Institute of Intelligent Systems

cCThis is an Open Access article distributed under the terms of the Creative Commons Attribution Non-Commercial License (http://creativecommons.org/licenses/by-nc/ 3.0/) which permits unrestricted noncommercial use, distribution, and reproduction in any medium, provided the original work is properly cited.

\begin{abstract}
Developing children's character must start from an early age. As children consider playing games a pleasant activity, exposing them to traditional games that involve cultural wisdom is an effective way to instill ethical norms and moral values in them. In Bali, many traditional games, such as Petaumpet and Tajog, require the children to be disciplined, cooperative, obedient and act honestly. Behaving in such a manner while playing can be an effective strategy for the character development of children. I Durma is one of the folklores that has been developed in the form of ICT-based game. This type of challenge game has an impact on the player's emotions. This study explains the relationship between game-factor, emotion, and character variables of game players. All three variables were obtained through questionnaire integrated in the game. The data obtained were analyzed using the neurofuzzy and backpropagation methods. The analysis result shows that there was a relationship between game-factor, emotional, and character variables. This is indicated by the output values of the neuro-fuzzy analysis. It was obtained that: training analysis ( $40.9 \pm 3.41)$, testing analysis $(42.0 \pm 2.64)$, and checking analysis $(42.4 \pm 2.75)$ with the difference between them ( $\Delta \mu<5 \%$ ) of 50 max scores. In other words, characters can be predicted from game-factor and players' emotion. The findings of this study can enable teachers to help students or users choose right games and control their emotions while playing as these can affect the character development of the children. We also show that children who were involved in playing the game responded positively to the game based on Balinese local wisdom.
\end{abstract}

Keywords: Balinese, Serious game, Game factor, Emotional, Character, Neuro-fuzzy

\section{Introduction}

Many traditional games in Bali, such as Petaumpet and Tajog, require children participating in the game to be disciplined, cooperative, obedient and act in an honest manner. It is believed that by adopting good attitude and behavior as part of these games can have a positive impact on the children's character development. Developing children's character should ideally start at an early age. As playing games is a pleasant activity for children, instilling ethical norms and moral values in children through these traditional games, which are passed on from one generation from another, is an effective strategy for children's character development. 
Games can play an important role in society by dealing with serious challenges a community is facing at a given time. The critical aspects of such a game is the relationship between the game and the educational content as the object of the game. However, it is not easy to develop such games. First, designing games often relies on the ideas and experiences of the designers and developers. Furthermore, it is an extremely challenging task to incorporate the educational elements in the game while at the same time prioritizing the entertainment value of the game [1]. And we know from the past experience that games, both traditional and modern, usually has always titled toward entertainment.

This also explains the ever-increasing popularity of games. Marston [2] has shown that adults prefer or would consider playing games in adventure, strategy, puzzles, and sports genres. This indicates that designing games involves taking into account the hobbies, interests, and fantasies of players, so as to produce new game patterns for most older people.

Games preferred by children usually involve action, adventures, and competitions. Moreover, children in rural areas generally prefer traditional games related to legends and folklore. In Bali, as a serious game on the topic of Balinese folklore "Cupak Gerantang" [3] for elementary school children as a learning aid for mathematics. Moreover, game design can also preserve Balinese culture by taking the folklore "I Rajapala" [4]. The players, in addition to being entertained, benefit from learning about Bali's cultural heritage.

Serious games are attracting significant interest from the gaming industry as well as the academics [5]. The most popular video game genre was action (27.1\%), but decreased by $5.4 \%$ until 2011 , and fell by only about $21.7 \%$. The sports games reached $17.6 \%$ in 2004 , increased by $2 \%$ to $19.6 \%$ in 2010 , and then decreased by $3.3 \%$ to $16.3 \%$ in 2011 . This indicates that, despite their popularity ebbing and flowing from time to time, games are still a popular option for most people as a choice for entertainment.

Since the last decade, many games have been developed for educational purposes. The results of a survey conducted by Pan [6] found that more students accepted interactive teaching modes based on educational games, and their learning efficiency increased. In [7], the author reported that the game-based virtual classroom was successful at the high school level: for several years, the number of active students grew from semester to semester, and gamification in education became increasingly popular. Mavridis et al. [8] integrated paper-based and gamebased tests for half-semester exams. The results showed a significant relationship, but statistically, there were no statistically significant differences between the two methods. Cowley et al. [9] developed a serious game design methodology to teach the concept and behavior of energy efficiency to users of public facility buildings through learning principles and interaction design for Green My Place: a massively multiplayer serious game. The overall attitude of students toward the STEM learning game model by Vate-U-Lan [10] was found to be very positive, with $45 \%$ of them preferring content delivery through an online browser and mobile applications. An important finding of this study was that game-based learning could be integrated into traditional classrooms in an effort to improve the learning approach process.

People with habits such as alcoholism and drug abuse, and propensity to violence need to receive serious intervention to overcome these tendencies. One solution to this problem can be using techniques to improve the mentality and character and change the habits of the individuals involved, something the government has established as a mental revolution. Considering their popularity among a large section of the society, games are increasingly being seen as an option for this purpose. There are several references related to character development, ethics, and good behavior. Suastra et al. [11] conducted research on developing character based on local Balinese wisdom and showed that core teaching procedures that can develop student character are exploration, elaboration, and confirmation in terms of various scientific, sociocultural, and historical perspectives. According to Lickona $[12,13]$, teaching by example includes treating children as friends who have the opportunity to imitate their parents. For this reason, parents should present examples of good character to their children, such as performing well at school, leadership, tolerance, kindness, accepting diversity, and delaying satisfaction, and drive them away from drug and alcohol abuse, smoking, violence, depression, laziness, and despair.

The application of the neural network and fuzzy model in various studies has greatly impacted various inventions, including a study by Lotfi and Karimi [14], on the higher accuracy of oil price prediction, to predict cadmium concentration in water resources by Sonmez et al. [15]. The neuro-fuzzy inference system combines fuzzy logic using artificial neural networks, where the input value of the neural network is processed first through a fuzzifier module, which makes ordinary numeric values cryptic values. Operations in the neural network are all cryptic, and the output is returned to normal values via the defuzzifier module. The combination of fuzzy systems and neural 
networks is capable of implementing human expertise in such a way that it can be used in the decision-making process in organizations. The relationship between the input and output variables can be used to predict the output variable if there is a suitable input variable. A neuro-fuzzy system can be used to develop a decision support system. In this study, we analyze the effectiveness of the neuro-fuzzy to predict the character as the output variable of two game-factor and emotional input variables based on Balinese local wisdom.

\section{Related Work}

\subsection{Balinese Serious Game}

The serious game that has been developed is titled I Durma, the son of a hunter named I Rajapala, who is married to an angel. The game is an episode of the I Rajapala game. As a child, I Durma loved playing traditional Balinese games with his peers, such as Petaumpet and Tajog. Figure 1 shows two stills from the game: in the first still, the children are chatting together, in the second, I Durma is playing Tajog.

Before starting the traditional Balinese game, I Durma talks to his friends about diverse things, such as norms, ethics, and manners based on religion, especially Hinduism. Everything he obtained was from his mother. The ethics and norms are very important for children, including: Catur Guru, Tri Kaya Parisuda, Sadripu, Sadatitayi, Tri Hita Karana, etc. Many previous studies have focued on serious games based on Balinese culture wisdom, such as "Cupak Gerantang" by Sukajaya et al. [3] and "I Rajapala" by Suwindra et al. [4]. According to the study by Winton [16], traditional approaches to character education must be abandoned for equality, diversity, active participation, critical thinking, social justice, and the common good.

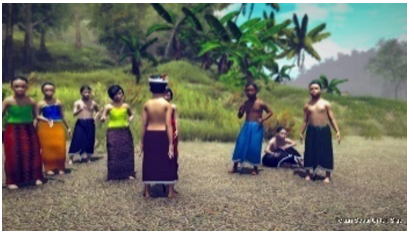

(a)

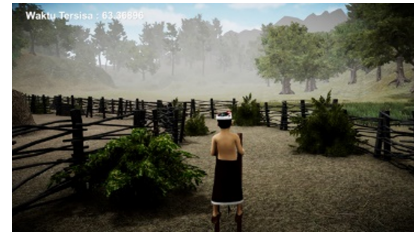

(b)
Figure 1. (a) I Durma is chatting with children and (b) he is playing Tajog.

\subsection{Game Factor, Emotional and Character}

Designing a serious game requires a strategy that combines fun and learning. Shi and Shih [17] explained that the macro design concept of a game consists of 11 important factors: objects, mechanisms, fantasy, values, interaction, freedom, narration, sensation, challenges, sociality, and mysteries. The combination of these factors eventually determines the quality of the serious game.

According to Kwon and Lee [18], a person's emotions can be categorized into four quartiles, each divided into three subquartiles: (1) Quartile 1 (pleased, happy, excited), (2) Quartile 2 (nervous, angry, annoying), (3) Quartile 3 (sleepy, bored, sad), and (4) Quartile 4 (calm, peaceful, relaxed). If a person's emotions are not controlled and managed properly, they will develop into habits. Moreover, habits developed based on negative emotions such as anger, boredom, and sleepiness can harm oneself and others around the individual. Herodotou et al. [19] explained that the emotions experienced by game players are related to their personal characteristics. Furthermore, emotions have been found to be negatively associated with the frequency of playing games.

Lickona $[12,13]$ proposed that a model from parents, teachers, and others can develop the character of children. According to Agung [20], character education is expected to be a tool and opportunity for students to develop a variety of good characters such as religiosity, honesty, integrity, tolerance, discipline, independent thinking, tenacity, creativity, patriotism, and friendliness. It is believed that children will develop favorable character if parents play their roles in introducing them to ethics, morals, and morality based on local culture.

\subsection{Neuro-Fuzzy and Serious Game}

The adaptive neuro-fuzzy inference system (ANFIS) is a model that can be used to predict several cases in various fields. One such case is a neuro-fuzzy model for predicting the effects of noise pollution on human work efficiency by Zaheeruddin and Garima [21], and other cases such as the others ANFIS for prediction are as follows. In [14], the ANFIS model shows higher accuracy than conventional neural networks in oil price prediction of the oil prices of the Organization of Petroleum Exporting Countries (OPEC). In [22], the analysis of the neurofuzzy membership function can predict inflation growth in Bali Province. In [23], neuro-fuzzy systems (NFS) can explicitly represent the input-output relationship model of complex problems and nonlinear systems in construction engineering and 
management (CEM) problems.

Artificial intelligence techniques based on fuzzy logic and neural networks when combined together are called NFS. This type of system is characterized by a fuzzy system, in which fuzzy sets and fuzzy rules are adjusted using input-output patterns. There are several different implementations of NFSs, and each set of researchers have defined their own hybrid neurofuzzy techniques. Murad and Malkawi [24] reported that an adaptive neuro-fuzzy system can be trained to detect current human emotions from a set of measured responses. In addition to e-learning components, which include instructors, learners, courses, and ICT, as well as learner performance, that aim to measure e-learning success. According to Dicheva and Dichev [25], the goal of game development is twofold: (1) comparing new results with previous data, and (2) analyzing the growth of gamification penetration in education. The study confirms that the mechanism of practice has outpaced understanding by researchers, while the penetration of gamification is still growing. Bae [26], aiming to improve the efficiency of the game development process, planned, designed, and developed a smart game based on a platform game engine. Living worlds offer a nonlinear, unscripted process for experiencing and safely learning the cognitive complexity and nuance of culture through emergent high-fidelity cultural training simulation [27]. Barbosa and his colleagues $[1,28]$ explained that serious game design needs to consider game factors and the concept of real-time strategy in the education and learning domain.

\section{Method}

\subsection{Research Process}

The research process, as illustrated in Figure 2, began by conducting a literature review and obtaining insights from the experts of the Balinese culture to determine the topic of the game to be developed. I Rajapala was a hunter married to an angel who gave birth to a son named I Durma. The next step was to design and program the game. The developed game consists of two episodes, namely, Episode-1: I Rajapala as a hunter (challenge game) and Episode-2: I Durma (a game for children's development). The questionnaires of game-factor emotional, and character are integrated into the game. After the validity and reliability were examined, an experiment was conducted. The questionnaire was displayed and worked on by the players during each episode. The results of the data analysis are reported in the form of a dissertation and a paper for publication.

\subsection{Neuro Fuzzy Inference System}

To predict the character player of the game, we analyzed the relationship between game-factor, emotional, and character by using the NFIS, whose design is shown in Figure 2.

The variables contained in the Sugeno Neuro-Fuzzy architecture scheme in Figure 3 can be explained as follows.

(1) The game-factor input variable $(F)$ describes the game player's response to the game factors with a membership function $\left(\mathrm{M}_{11}, \mathrm{M}_{12}, \mathrm{M}_{13}, \mathrm{M}_{14}, \mathrm{M}_{15}\right)$. The game factors consist of 11 aspects represented in the serious game, including goals, mechanisms, fantasies, values, interactions, freedom, narratives, sensations, challenges, sociality, and mystery.

(2) Emotional input variable $(E)$ describes the emotional level of the game player with the membership function $\left(\mathrm{M}_{21}\right.$, $\mathrm{M}_{22}, \mathrm{M}_{23}, \mathrm{M}_{24}, \mathrm{M}_{25}$ ), which consists of 12 aspects, including spirit, happiness, happiness, nervousness, anger, irritation, sleepy, bored, sad, peaceful, and relentless.

(3) The character output variable $(O)$ is a game player character with 10 types of character aspects, including independence,

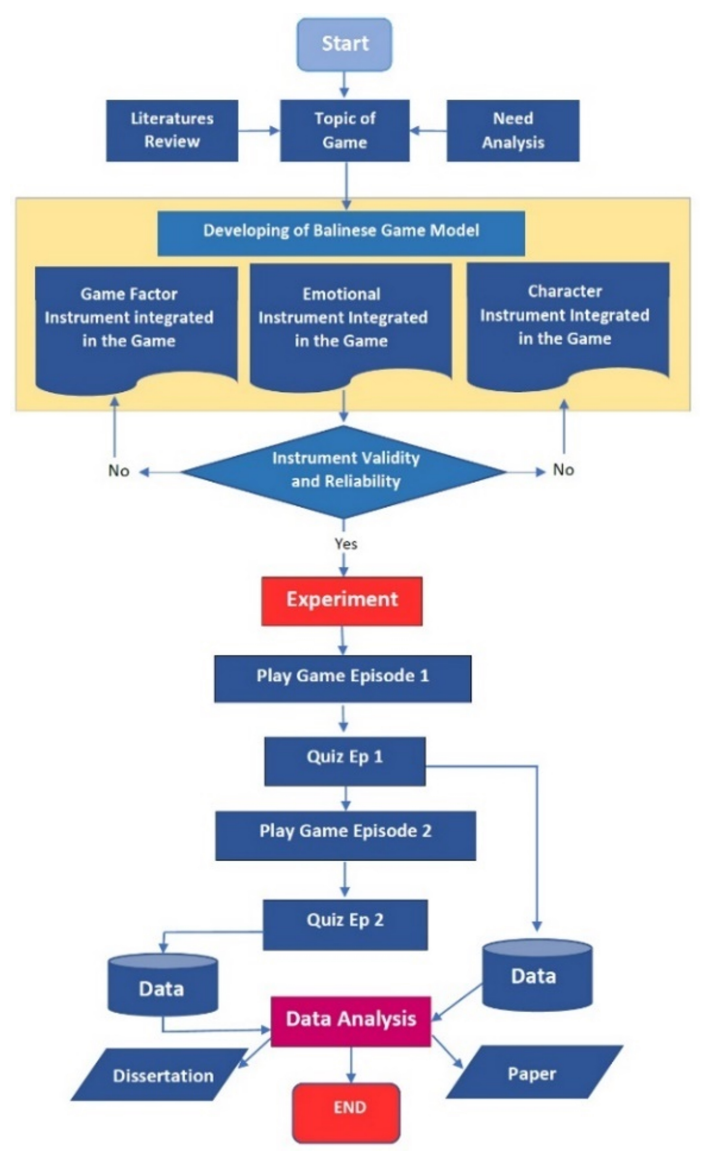

Figure 2. Process of research. 


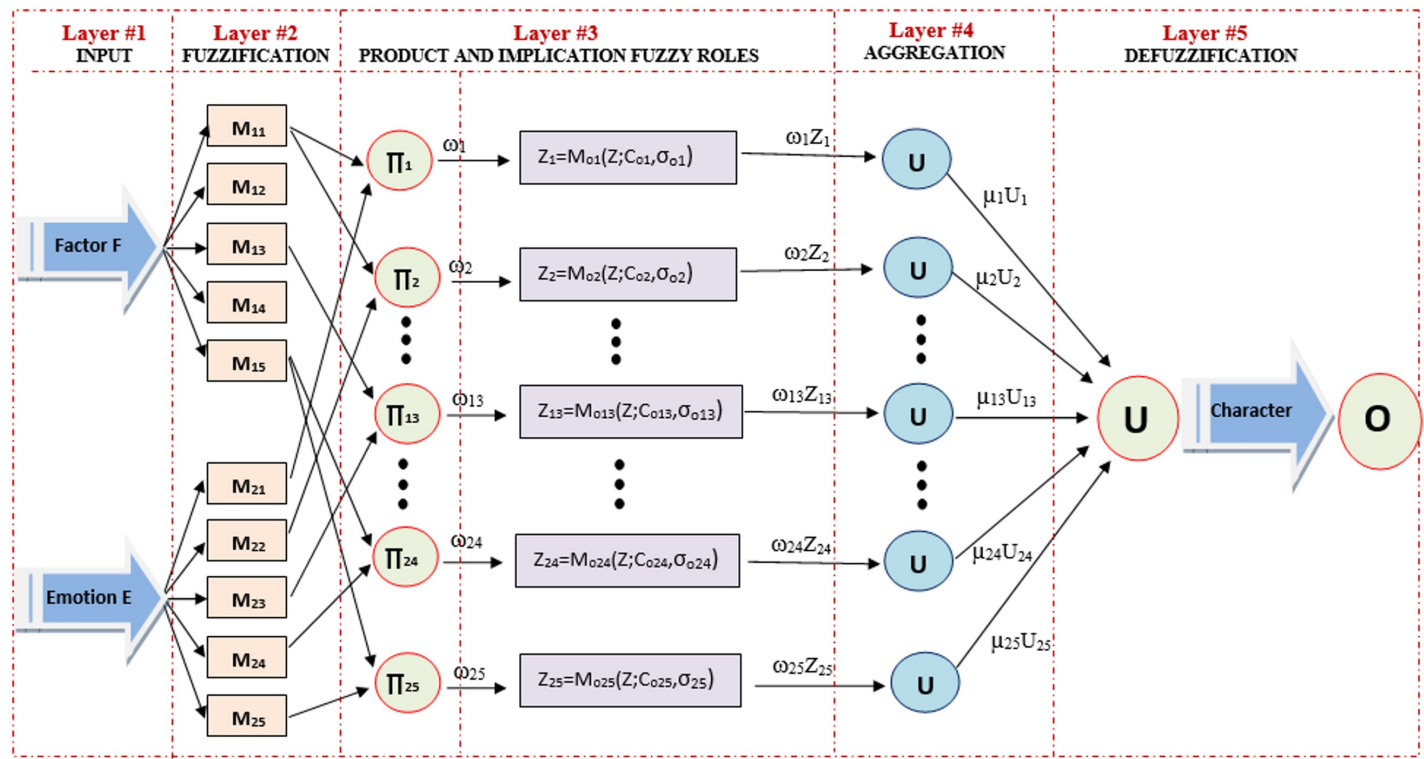

Figure 3. Sugeno neuro-fuzzy architecture scheme.

resilience, discipline, religion, honest, tolerant, patriotic, creative, integrity, and friendly.

In this study, the number of membership functions (MF) for the input factors factor $(\mathrm{F})$, emotion $(\mathrm{E}), 5$, and 5 can be interpreted linguistically from fuzzy grids. Every possible combination of fuzzy inputs is represented by a rule based on the Sugeno FIS model. The number of rules of the NFIS model is $5 \times 5=25$. Figure 3 shows the architecture of Sugeno NFIS, where the circle indicates the fixed node and the rectangle indicates the adaptive node. The Sugeno NFIS roles can be written as:

(1) If ((F is $\left.\mathbf{M}_{11}\right)$ and (E is $\left.\mathbf{M}_{21}\right)$ ),

then $\mathbf{Z}_{1}=\mathbf{M}_{o 1}\left(\mathbf{z} ; \mathbf{c}_{o 1}, \sigma_{o 1}\right)$.

(2) If ( $\left(F\right.$ is $\left.M_{11}\right)$ and ( $E$ is $\left.\left.M_{22}\right)\right)$, then $\mathbf{Z}_{2}=\mathbf{M}_{o 2}\left(\mathbf{z} ; \mathbf{c}_{o 2}, \sigma_{o 2}\right)$.

(13) If $\left(\left(\mathbf{F}\right.\right.$ is $\left.\mathbf{M}_{13}\right)$ and $\left(\mathrm{E}\right.$ is $\left.\left.\mathbf{M}_{23}\right)\right)$, then $\mathbf{Z}_{13}=\mathbf{M}_{o 13}\left(\mathbf{z} ; \mathbf{c}_{o 13}, \sigma_{o 13}\right)$.

(24) If $\left(\left(\mathbf{F}\right.\right.$ is $\left.M_{15}\right)$ and ( $E$ is $\left.\left.M_{24}\right)\right)$, then $\mathbf{Z}_{24}=\mathbf{M}_{o 24}\left(\mathbf{z} ; \mathbf{c}_{o 24}, \sigma_{o 24}\right)$.

(25) If $\left(\left(\mathbf{F}\right.\right.$ is $\left.\mathbf{M}_{15}\right)$ and $\left(\mathrm{E}\right.$ is $\left.\left.\mathbf{M}_{25}\right)\right)$,

then $\mathbf{Z}_{25}=\mathbf{M}_{o 25}\left(\mathbf{z} ; \mathbf{c}_{o 25}, \boldsymbol{\sigma}_{o 25}\right)$.

In general, the output is written as $Z_{k}=M_{o k}\left(z ; C_{o k}, \sigma_{o k}\right)$ with $k=1,2, \ldots, 25$, where $\boldsymbol{M}_{i j}, \boldsymbol{Z}_{\boldsymbol{k}}$, and $\boldsymbol{M}_{\boldsymbol{o k}}$ represent the $j$ th MF of the $i$ th input, the $k$ th output role, and the $k$-MF output, respectively. In the Sugeno logic equation, FIS roles $C_{o k}$ and $\sigma_{o k}$ are the consequence parameters that characterize the forms of the MF output.

The architecture of Sugeno FIS consists of five layers: input, fuzzification, product and implication roles, aggregation, and de-fuzzification, with the following description:

Layer \#1: This layer is an input crisp consisting of two input variables $\mathrm{F}$ and $\mathrm{E}$.

Layer \#2: This layer converts the input crisp value to a fuzzy value using the MF input.

Layer \#3: This layer performs the fuzzification process, where the weight or strength factor of each role pair is calculated. The weighting factor of each role, which is expressed as $\omega_{k}$, is determined by evaluating membership statements in the antecedents of that role. This is solved by changing the input value to the MF value using the MF input at Layer \#2 and then applying the "and" operator to the MF value. The "and" operator corresponds to the multiplication of the MF input values. Then, the strength factors of the roles are calculated using the following formula:

$$
\begin{aligned}
\text { (1) } \omega_{1} & =\mathbf{M}_{11}(\mathbf{F}) \cdot \mathbf{M}_{21}(\mathbf{E}) . \\
\text { (2) } \omega_{2} & =\mathbf{M}_{11}(\mathbf{F}) \cdot \mathbf{M}_{22}(\mathbf{E}) . \\
& \\
& \\
\text { (13) } \omega_{13} & =\mathbf{M}_{13}(\mathbf{F}) \cdot \mathbf{M}_{23}(\mathbf{E}) .
\end{aligned}
$$




$$
\begin{aligned}
& \text { (24) } \omega_{24}=\mathbf{M}_{15}(\mathbf{F}) \cdot \mathbf{M}_{24}(\mathbf{E}) . \\
& \text { (25) } \omega_{25}=\mathbf{M}_{15}(\mathbf{F}) \cdot \mathbf{M}_{25}(\mathbf{E}) .
\end{aligned}
$$

In this layer, the implications of each MF output can be calculated using the equation:

$$
\mathbf{M}_{i m p, k}=\boldsymbol{\omega}_{k} \mathbf{Z}_{k} k=1,2, . ., 25,
$$

where $M_{i m p, k}$ represents the implications of MF output.

Layer \#4: This layer is an aggregate formed from the average yield of MF and $M_{o}(Z)$ output using the union $(\cup)$ operator by using the following equation:

$$
M_{o}(Z)=\bigcup_{k=1}^{25} M_{i m p, k}=\bigcup_{k=1}^{25} \omega_{k} Z_{k}=\bigcup_{k=1}^{25} M_{o k}\left(z ; c_{o k}, \sigma_{o k}\right) .
$$

The types of MF output $\boldsymbol{M}_{\boldsymbol{o k}}$ are the types of each MF. The "union" operator is formed using the maximum operator.

Layer \#5: This layer is a de-fuzzification that is formed using the centroid of the area method, with the following equation:

$$
\operatorname{Output}(O)=\frac{\int_{z} M_{o}(z) z d z}{\int_{z} M_{o}(z) d z} .
$$

To determine the tendency of the form of dataset graphics, an analysis of the membership functions of the data set was carried out. The tendency of the form of datasets can be determined from the smallest root-mean-square-error (RMSE) value of the Sugeno neuro-fuzzy analysis. Each membership function was analyzed using two methods: the backpropagation method and the neuro-fuzzy method. The types of MF that would be analyzed consists of eight types [29], namely: (1) Triangular MF, $f=M y(x)=\operatorname{trim} f(x ; a, b, c)$; (2) Trapezoidal MF, $f m y(x)=\operatorname{trapm} f(x ; a, b, c, d)$; (3) Generalized Bell-shaped MF with $f=M y(x)=\operatorname{gbellmf}(x ; a, b, c)$; (4) Gaussian MF, $f=M y(x)=\operatorname{gaussm} f(x ; \sigma, c)$; (5) Two Gaussian MF, $f=M y(x)=$ gauss $2 m f(x ; \sigma, c)$; (6) Sigmoidal MF, $f=M y(x)=\operatorname{sigmf}(x ; a, c)$; (7) Difference sigmoidal MF, $f=M y(x)=\operatorname{dsigm} f(x ; a, c)$; and (8) Product sigmoidal MF, $f=M y(x)=\operatorname{psigm} f(x ; a, c)$, where $x$ is variable, and $a, b, c, d$ are constants. All of the MF types to determine their RMSE were analyzed using the Simulink in the Fuzzy Logic Toolbox for MATLAB [29].

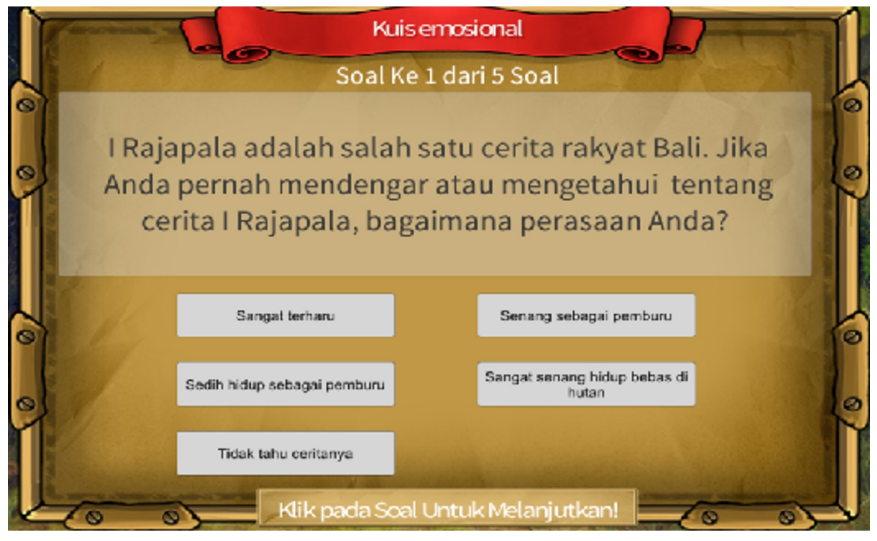

Figure 4. An example quiz integrated in the game.

\subsection{Instruments of Research}

There were three instruments in the form of questionnaires in accordance with the variables to be measured in this study: game-factor questionnaire, emotional questionnaire, and character questionnaire. The three questionnaires were integrated in the game, in the form of a quiz that appeared on the sidelines of the game as the players played the game.

Figure 4 shows an example of an emotional quiz integrated in the game. The entire questionnaire is presented in the appendix. Game players will respond to each quiz, and the answers to each quiz given are recorded in the game database system in the form of a Likert scale (score 1 to 5).

Each questionnaire consists of two parts that appear in each episode, namely, Episode 1 with five items (Q1EP1-Q5EP1) and Episode 2 with five items (Q1EP2-Q5EP2). The validity and reliability of the questionnaires were examined, with significance at $p=0.01$. This can be shown from the scientific indices of each item and the Cronbach's alpha values of each questionnaire as follows.

Based on the output of the SPSS Pearson correlation analysis, the correlation coefficient $r$ of each game-factor questionnaire item was as follows: Episode 1 (rQ1Ep1 $=0.444$, rQ2Ep1 $=0.425$, rQ3Ep1 $=0.415, \mathrm{rQ} 4 \mathrm{Ep} 1=0.459$, rQ5Ep1 $=$ 0.426 ), and Episode 2 (rQ1Ep2 $=0.470$, rQ2Ep2 $=0.539$, rQ3Ep2 $=0.424, \mathrm{rQ} 4 \mathrm{Ep} 2=0.445, \mathrm{rQ} 5 \mathrm{Ep} 2=0.422)$, and reliability (Cronbach's alpha $=0.684$ ).

The correlation coefficient $r$ of each emotional questionnaire item was also as follows: Episode 1 (rQ1Ep1 $=0.484$, rQ2Ep1 $=0.504, \mathrm{rQ} 3 E p 1=0.524, \mathrm{rQ} 4 \mathrm{Ep} 1=0.347$, rQ5Ep1 $=$ 0.492), and Episode 2 (rQ1Ep2 $=0.481$, rQ2Ep2 $=0.287$, rQ3Ep2 $=0.499, \mathrm{rQ} 4 \mathrm{Ep} 2=0.526, \mathrm{rQ} 5 \mathrm{Ep} 2=0.327)$, and reliability $(\mathrm{Cron}-$ bach's alpha $=0.686$ ). 
Likewise, the correlation coefficient $r$ of each character questionnaire item was as follows: Episode $1(\mathrm{rQ1Ep} 1=0.450$, rQ2Ep1 $=0.379$, rQ3Ep1 $=0.556$, rQ4Ep $1=0.464$, rQ5Ep1 $=$ 0.518 ), and Episode 2 (rQ1Ep2 $=0.415$, rQ2Ep2 $=0.270$, rQ3Ep2 $=0.268, \mathrm{rQ} 4 \mathrm{Ep} 2=0.341, \mathrm{rQ5Ep} 2=0.363$ ), and reliability (Cronbach's alpha $=0.655)$.

\section{Experiment and Data Analysis}

\subsection{Experiment for Children}

Game trials were conducted for junior high school students 12-14 years old, as shown in Figure 5. A total of 18 children accustomed to playing games participated in the study. Each child played the game 10-15 times. The data were recorded every time the game played was recorded in a database system that was integrated in the game.

Figure 5 shows that the children learning together how to play the game before the game trial, and a child testing play game alone.

\subsection{Design of Data Analysis}

The design of data analysis consists of three variables, namely, game-factor and emotional, which were input variables, and character, which was the output variable. Their relationships were analyzed using the Sugeno neuro-fuzzy. The design of the method is shown in Figure 6.

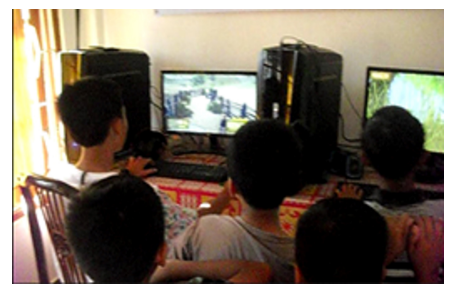

(a)

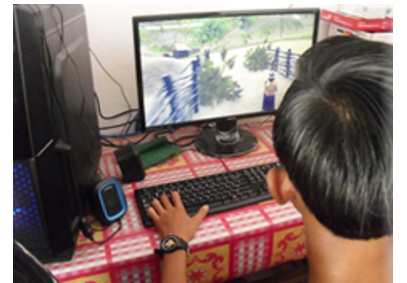

(b)
Figure 5. (a) The children learning together how to play the game before the game trial and (b) a child testing a game alone.

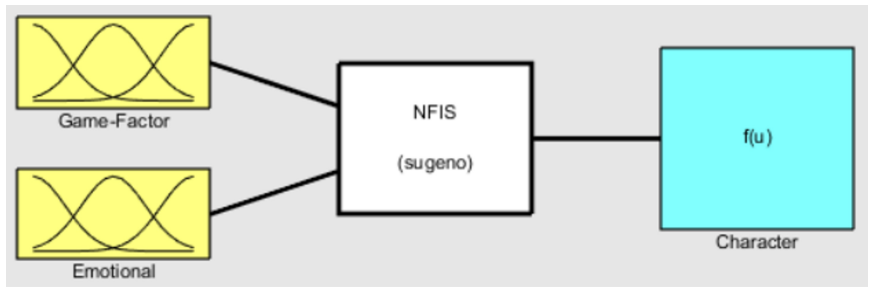

Figure 6. Design of Sugeno neuro-fuzzy method.
The Sugeno neuro-fuzzy analysis was performed using both the backpropagation method and the neuro-fuzzy method. Prediction of slope stability using an ANFIS based on clustering methods [30] [31]. In this study, data grouping was carried out with all, odd, and even data sequences for training, testing, and checking. The fair of data consists of a game-factor and emotional as an input, and character as an output. Data analysis was performed using the Sugeno neuro-fuzzy method with the help of the Simulink/MATLAB R2014b application [29]. The data analysis to determine the relationship between variables begins with an analysis to determine the tendency of the membership function (MF) to form fuzzy. The analysis of the inclination shape of the slope was determined by the training dataset using membership function models in the neuro-fuzzy analysis, namely, triangular membership function (trimf), trapezoidal membership function (trapmf), generalized bell membership function (gbellmf), Gaussian membership function (gaussmf), two generalized bell membership function (gauss $2 \mathrm{mf}$ ), sigmoidal membership function (sigmf), difference sigmoidal membership function $(\operatorname{dsigm} f)$, and product sigmoidal membership function ( $p$ sigm $f$ ). The most suitable membership function model was determined based on the smallest RMSE from the training results.

\subsection{Description of Research Results}

The results of the game experiment carried out on 18 children obtained three types of variable data: (1) game-factor variables, (2) emotional variables, and (3) character variables. Each child played games 10-15 times while answering the questionnaire; the resulting data were recorded and integrated into the game. Thus, 205 score data samples were obtained for each variable All three variables were formed in a $205 \times 3$ matrix of the data pairs. Visually, the variance of the score is shown in Figure 7.

Figure 7 shows that between pairs of variables, the value varies significantly, where blue represents the game-factor variable, pink the emotional variable, and light brown the character

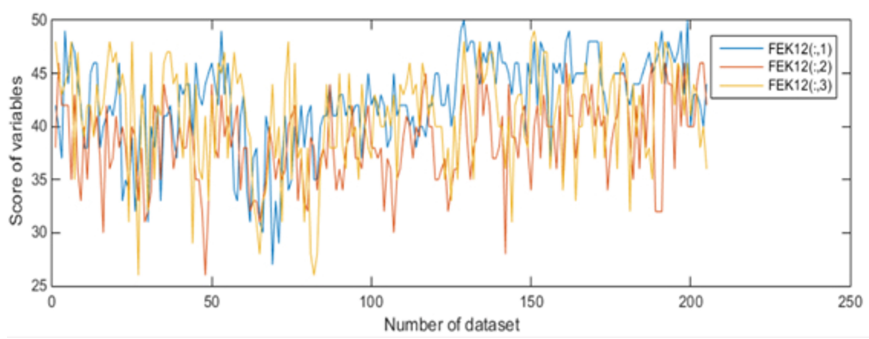

Figure 7. Graph of data set samples. 


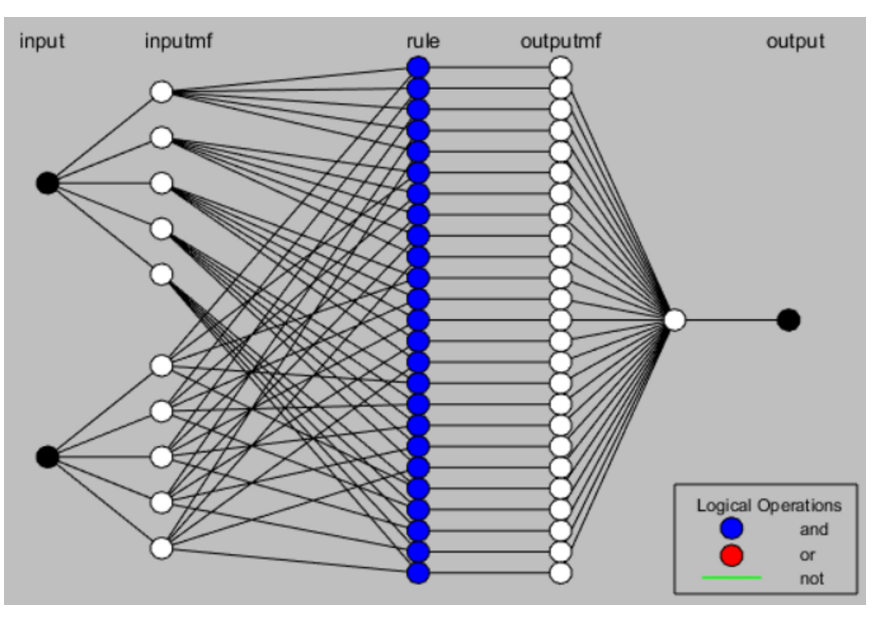

Figure 8. Structure of Sugeno neuro-fuzzy method.

variable. The relationship between these variables was examined through an analysis using the Sugeno neuro-fuzzy method. All data pairs were classified into three groups of data pairs, namely the first data group for training, the second group for testing, and the third group for checking. Bearing in mind that the number of data samples was relatively small, the determination of data groups was carried out conventionally and rationally, namely (1) all data for training or learning, (2) odd data for testing, and (3) even data for checking. The structural scheme of Sugeno neuro-fuzzy method is shown in Figure 8.

Figure 8 shows that the Sugeno neuro-fuzzy method structure scheme consists of five layers: (1) the input layer consists of two inputs (game-factor and emotional); (2) the input MF layer consists of $5 \mathrm{MF}$ each; (3) role layer consists of $5 \times 5=25$ roles; (4) the output MF layer consists of $25 \mathrm{MF}$; (5) the output layer consists of one output (character).

\subsection{Result of Data Analysis}

\subsubsection{Training data analysis}

Training data analysis to determine the RMSE of each membership function model (trimf, trapmf, gbellmf, gaussmf, gauss $2 m f$, pimf, dsigmf, and psigmf) were carried out with two inputs, each with a membership number of $5(5 \times 5$ rules number), epoch between 100-600, backpropagation, and neuro-fuzzy. The results of the training and learning analyses are presented in Table 1.

Based on Table 1, the smallest RMSE value was generated from the training analysis with a difference sigmoidal membership function (dsigmf) model, which was 3,41291 (brown cell mark) at epochs $=500$. It means that the dsigmf model was

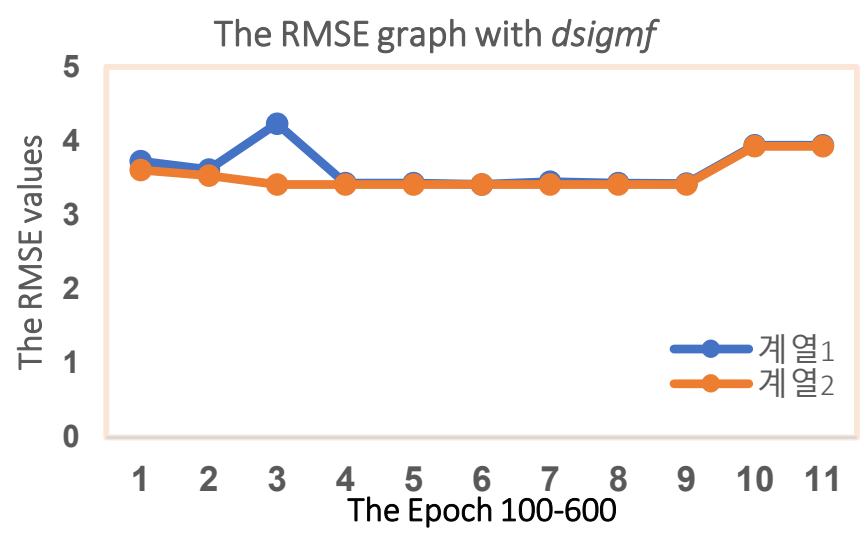

Figure 9. RMSE graph with dsigmf.

considered the most suitable input for the neuro fuzzy method to predict output.

Learning or training analysis was conducted on the eight types of MF models with epochs: (100, 150, 200, 250, 300, 350, $400,450,500,550$, and 600), and with two backpropagation and hybrid methods, 88 pairs of RMSE values were obtained. Of the 88 pairs of RMSE values, eight pairs (red text mark) or $9.09 \%$ of the RMSE values with the backpropagation method were smaller than the RMSE values with the neuro-fuzzy method. This means that the error rate of the training analysis with the neuro-fuzzy method is lower than the error rate with the backpropagation method. In other words, the neuro-fuzzy method is better than the backpropagation method.

Figure 9 shows that the training analysis with the difference sigmoidal membership function graphically the value of RMSE based on the epoch with the neuro-fuzzy method (series2) is smaller than the value of RMSE with the backpropagation method (series 1 ). The same was obtained from the training analysis of each membership function model at epoch $=500$. The same thing based on the membership function models, graphically also shows that the RMSE value with the neurofuzzy method (series2) is smaller than the RMSE value with the backpropagation method (series1), as shown in Figure 10.

Based on Figure 11, it can be explained that the display patterns of the relationship between game-factor, emotional, and character of the membership function models appear to be almost the same or similar between the neuro-fuzzy and back propagation. There were exceptions; however, the membership function pattern, gbellmf pattern, and gauss $2 m f$ pattern, as presented in Figures 12 and 13, were different.

In terms of the RMSE values, the neuro-fuzzy method is smaller than the backpropagation method. This is clearly ob- 
Table 1. RMSE values of membership function (MF) training

\begin{tabular}{|c|c|c|c|c|c|c|c|c|c|c|c|c|}
\hline \multirow{2}{*}{ MF } & \multirow{2}{*}{ Method } & \multicolumn{11}{|c|}{ RMSE values with epoach } \\
\hline & & 100 & 150 & 200 & 250 & 300 & 350 & 400 & 450 & 500 & 550 & 600 \\
\hline \multirow{2}{*}{ trimf } & Backpropagation & 3.91261 & 3.91233 & 3.90157 & 3.90845 & 3.90888 & 3.89136 & 3.89413 & 3.87665 & 3.88443 & 4.10996 & 3.71355 \\
\hline & Neuro-fuzzy & 3.84692 & 3.84492 & 3.84492 & 3.84138 & 3.84180 & 3.84115 & 3.84110 & 3.84092 & 3.84013 & 3.71381 & 3.70724 \\
\hline \multirow{2}{*}{ trapmf } & Backpropagation & 3.70564 & 3.71071 & 3.71225 & 3.71886 & 3.72104 & 3.73010 & 3.73189 & 3.74317 & 3.74705 & 3.63525 & 4.17197 \\
\hline & 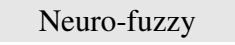 & 3.70114 & 3.70658 & 3.71431 & 3.71431 & 3.72437 & 3.72437 & 3.73715 & 3.73715 & 3.75762 & 3.63641 & 3.75305 \\
\hline \multirow{2}{*}{ gbellmf } & Backpropagation & 3.68699 & 3.68553 & 3.74014 & 3.66648 & 3.66438 & 3.76226 & 3.86020 & 3.86493 & 3.93959 & 4.16973 & 4.25481 \\
\hline & Neuro-fuzzy & 3.61933 & 3.47734 & 3.42471 & 3.42471 & 3.42457 & 3.42451 & 3.42372 & 3.42371 & 3.42299 & 3.48329 & 3.48467 \\
\hline \multirow{2}{*}{ gaussmf } & Backpropagation & 4.13565 & 3.73080 & 3.73041 & 3.61325 & 3.60686 & 3.62005 & 3.61918 & 3.60344 & 3.64134 & 4.13378 & 3.54818 \\
\hline & zzy & 3.75209 & 3.68299 & 3.60824 & 3.56897 & 3.56896 & 3.56850 & 3.56864 & 3.56868 & 3.56817 & 3. & 3.53315 \\
\hline \multirow{2}{*}{ gauss $2 \mathrm{mf}$} & Backpropagation & 3.67837 & 3.67143 & 3.87551 & 3.58637 & 3.50341 & 3.46763 & 4.30248 & 3.51921 & 3.49693 & 3.46384 & 3.4641 \\
\hline & Neuro-fuzzy & 3.68719 & 3.54526 & 3.57187 & 3.50307 & 3.46797 & 3.46797 & 3.51506 & 3.49674 & 3.49356 & 3.47970 & 3.46589 \\
\hline \multirow{2}{*}{ pimf } & Backpropagation & 3.81024 & 4.26273 & 4.39607 & 3.71909 & 3.54303 & 3.54302 & 3.54286 & 3.54292 & 3.54250 & 4.13374 & 3.5459 \\
\hline & -fuzzy & 3.82149 & 3.77939 & 3.74066 & 3.55349 & 3.54136 & 3.54131 & 3.54128 & 3.54124 & 3.54124 & 3.54482 & 3.54139 \\
\hline \multirow{2}{*}{ dsigmf } & Backpropagation & 3.72676 & 3.61261 & 4.23532 & 3.43212 & 3.43185 & 3.41579 & 3.45108 & 3.43266 & 3.42399 & 3.94002 & 3.94002 \\
\hline & Neuro-fuzzy & 3.60862 & 3.53048 & 3.41482 & 3.41482 & 3.41431 & 3.41382 & 3.41382 & 3.41326 & 3.41291 & 3.92837 & 3.92837 \\
\hline \multirow{2}{*}{ psigmf } & Backpropagation & 4.47560 & 4.47415 & 4.38513 & 4.38165 & 4.37624 & 4.17226 & 4.17127 & 4.17827 & 4.16903 & 4.16818 & 4.16779 \\
\hline & Neuro-fuzzy & 3.74417 & 4.42793 & 4.38396 & 4.38048 & 4.17226 & 4.17226 & 4.16970 & 4.16857 & 4.16739 & 4.16685 & 4.16639 \\
\hline
\end{tabular}

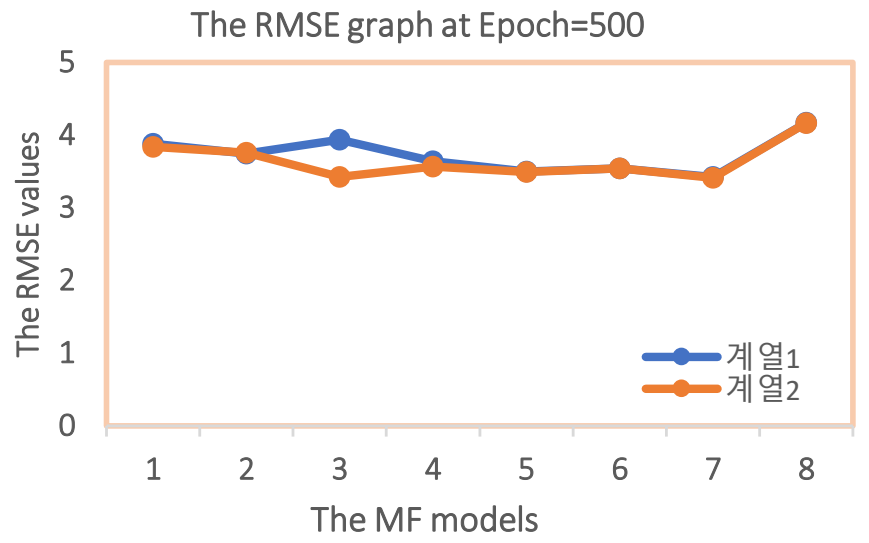

Figure 10. The RMSE graph at epoch $=500$.

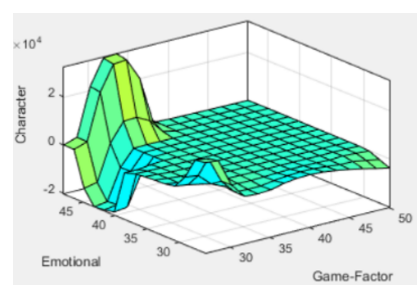

(a)

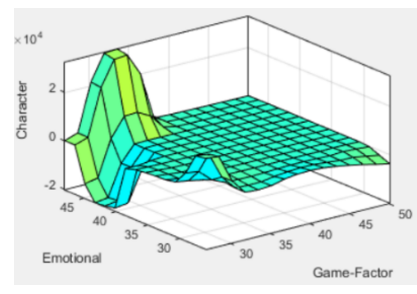

(b)

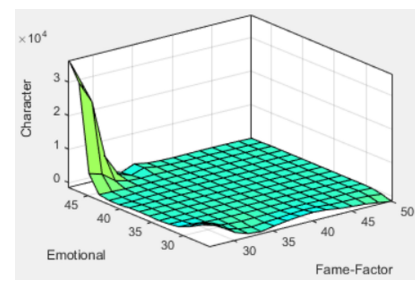

(a)

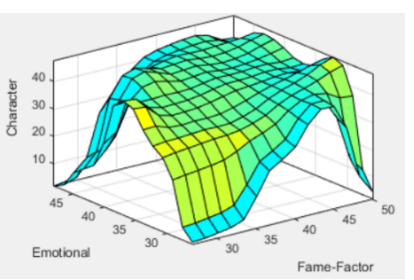

(b)
Figure 12. Graph display training data with gbellmf pattern: (a) the neuro-fuzzy method and (b) backpropagation method.

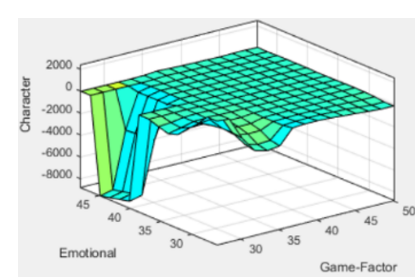

(a)

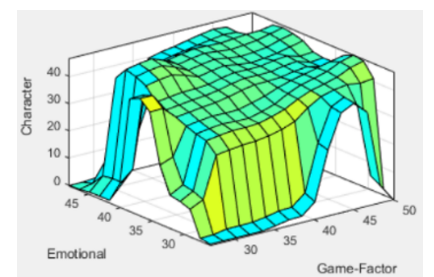

(b)
Figure 13. Graph display training data with gauss $2 m f$ pattern: (a) the neuro-fuzzy method and (b) backpropagation method.

relationship between game-factor, emotional and character. In other words, the character of a game player can be predicted from the game-factor and emotional with a mean of 40.9 , and an RMSE of 3.41291. served in Figure 8. Based on the analysis of training data that has been done it can be concluded that with the NFIS there is a
Figure 11. Graph display training data with $d \operatorname{sigm} f$ pattern: (a) the neuro-fuzzy method and (b) backpropagation method.

301 | I. Nyoman Putu Suwindra, I. Ketut Gede Darma Putra, Made Sudarma, and Nyoman Putra Sastra 


\subsubsection{Data testing and checking}

Testing and checking of data was carried out using the same method, namely, the Sugeno neuro-fuzzy (hybrid and backpropagation) method and the difference sigmoidal membership function $($ dsigm $f)$ as input to epoch $=500$. The results of the analysis were as follows: for testing data analysis, the value of RMSE $=2.64309$ with both the hybrid and backpropagation methods. The verification analysis shows that the value of $\mathrm{RMSE}=2.75212$ (neuro-fuzzy) is smaller than the value of RMSE $=2.77419$ (backpropagation method). This means that for both testing data and checking data, the hybrid neuro-fuzzy is interpreted according to training data analysis. The graphic display of the relationship between game-factor, emotional, and character for both analyses is shown in Figures 14 and 15.

\subsubsection{The effectiveness of neuro-fuzzy analysis}

A summary of the data analysis results of the neuro-fuzzy with a difference sigmoidal membership function (dsigmf) as $\mathrm{mf}$ input at epoch $=500$ is presented in Table 2.

The results displayed in Table 2 can be explained as follows. Based on the third RMSE value of the analysis, that is, training $(3.41<3.42)$ or $(3.41291<3.42399)$ in Table 1 , testing $(2.64 \leq 2.64)$, and checking $(2.75<2.77)$ show that the hybrid method is better than the backpropagation method. When viewed from the average output value of character variables

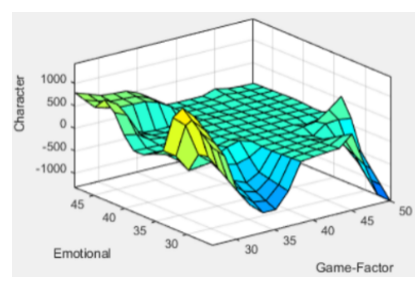

(a)

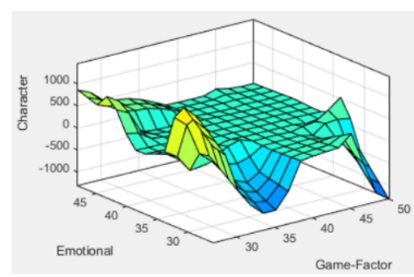

(b)
Figure 14. Graph display testing data with $d \operatorname{sigm} f$ pattern: (a) the neuro-fuzzy method and (b) backpropagation method.

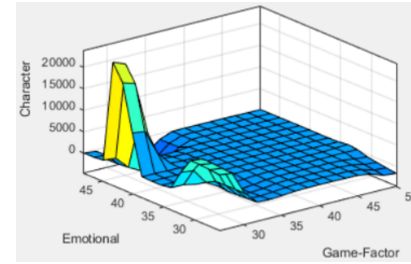

(a)

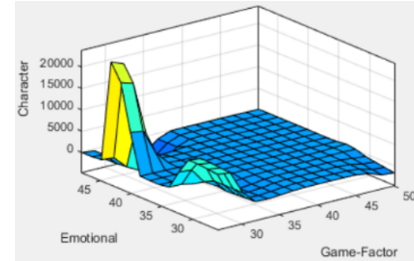

(b)
Figure 15. Graph display checking data with $\operatorname{dsigmf}$ pattern: (a) the neuro-fuzzy method and (b) backpropagation method.

from the three neuro-fuzzy analyses, the numbers show some varieties, namely training (40.9), testing (42.0), and checking (42.4). The average input values of the game-factor and emotional variables showed 38.5 and 37.0, respectively.

\subsubsection{Discussion}

The smallest RMSE value was generated from the training analysis using the difference sigmoidal membership function $($ dsigm $)$ model, which was 3.41291 at epochs $=500$. It means that the difference sigmoidal membership function (dsigm $f$ ) model the most suitable input for the neuro-fuzzy method to predict output. It is suitable for the prediction of slope stability using an ANFIS based on clustering methods [30].

Our analysis reveals that the relationship between gamefactor, emotional, and character variables was the game player analyzed using the neuro-fuzzy method. This is indicated by the output values of the neuro-fuzzy analysis. It was obtained that: training analysis $(40.9 \pm 3.41)$, testing analysis $(42.0 \pm 2.64)$, and checking analysis $(42.4 \pm 2.75)$ with the difference between them $(\Delta \mu<5 \%)$. In other words, characters can be predicted from game factors and emotional players. These results indicate compliance with the neuro-fuzzy model for predicting in many cases, namely, by Lotfi and Karimi [14], Zaheeruddin and Garima [21], Raharja, et al. [22], and Tiruneh et al. [23].

Based on the analysis results, it can be interpreted that the

Table 2. Summary of the neuro-fuzzy analysis

\begin{tabular}{cccccccc}
\hline \multirow{2}{*}{ Data analysis } & \multirow{2}{*}{$\begin{array}{c}\text { Mean of } \\
\text { game-factor }\end{array}$} & \multirow{2}{*}{$\begin{array}{c}\text { Mean of } \\
\text { emotional }\end{array}$} & \multicolumn{4}{c}{ Sean and RMSE of character with method: } \\
\cline { 6 - 8 } Descriptive & 42.3 & 38.6 & $41.0 \pm 6.43$ & Neuro-fuzzy & Backpropagation & $\Delta \mu(\%)$ \\
Training & 38.5 & 37.0 & & $40.9 \pm 3.41$ & $39.7 \pm 3.42$ & 2.62 & 5.25 \\
Testing & 38.5 & 37.0 & & $42.0 \pm 2.64$ & $41.9 \pm 2.64$ & 0.94 & 2.56 \\
Checking & 38.5 & 37.0 & & $42.4 \pm 2.75$ & $43.0 \pm 2.77$ & 3.54 & 7.67 \\
\hline
\end{tabular}


character can be predicted from the game-factor and emotion of the player. This can be explained by the analysis of the mean difference between the descriptive statistical method and the neurofuzzy method (hybrid $=1.84 \%$; backpropagation $=1.12 \%$ ). The difference in mean analysis of the neuro-fuzzy method between training and testing $(2.62 \%)$, testing to checking $(0.94 \%)$, and training to checking (3.54\%). Likewise, the difference in mean analysis of the backpropagation method between training and testing $(5.25 \%)$, testing to checking $(2.56 \%)$, and training to checking $(7.67 \%)$. This means that the analysis using the neurofuzzy method is better at determining the relationship between game-factor, emotional, and character variables $(\Delta \mu<5 \%)$ compared with the backpropagation method. This is supported by Shi and Shih [17] on the macro design concept of a game, Kwon and Lee [18] on the category of a person's emotions, and Lickona [12,13] about the development of the children's character. This means that games based on local Balinese wisdom can mediate the development of children's character, as expressed by Sukajaya et al. [3] in the Balinese game "Cupak Gerantang," and Suwindra et al. [4] in the game development to preserve Balinese culture by incorporating the folklore "Rajapala."

Furthermore, the children who played the game respond positively to the game based on game factors with a mean of 38.5 out of 50 max scores, and an emotional level with a mean of 37 out of 50 max scores. This will impact on the success of the learning process, as expressed by Winton [16], traditional approaches to character education; Barbosa et al. [1, 28], serious game design needs to consider game factors and the real-time strategy concept; Dicheva and Dichev [25], the goal of game development; and Bae [26], for the efficiency of the game development process. The new findings of this study were that the neuro-fuzzy method can determine the relationship between game factors, emotions, and children's characteristics.

The implication of further research is the development of a neuro-fuzzy-based decision support system. For the benefit of the teacher or each user, the teacher can recommend students or users so that playing games avoids types of games that have bad effects on character development of children. For example, war games or games involving violence can have negative impact on children. Likewise, it is important to teach the children that they should be able to control emotions and reduce irritability while playing games, as it can have a bad impact on their over well-being and character development.

The neuro-fuzzy superiority with respect non-fuzzy method is that the neuro-fuzzy method, in the further research can be carried out about the decision support system based on neuro-fuzzy that integrated in the game. It is possible that the regression method would be difficult to integrate.

\section{Conclusion}

The present study found a relationship between game-factor, emotional, and character variables of children playing a game, when analyzed using the neuro-fuzzy method. This is indicated by the output values of the neuro-fuzzy analysis. It was obtained that: training analysis $(40.9 \pm 3.41)$, testing analysis $(42.0 \pm$ $2.64)$, and checking analysis $(42.4 \pm 2.75)$ with the difference between them $(\Delta \mu<5 \%)$ out of 50 max scores. In other words, characters can be predicted from game factors and emotions of the players.

The finding can help teachers advise users to choose the type of game and control their emotions while playing games as it affects their character development. Furthermore, children who were involved in playing the game responded positively to the game based on Balinese local wisdom.

The implication of further research is the development of a neuro-fuzzy-based decision support system. Using that system, the teacher can help students or users avoid playing games that have a negative impact on children's character development.

\section{Conflict of Interest}

No potential conflict of interest relevant to this article was reported.

\section{Acknowledgment}

The authors thank Mr. Prof. Dr. I Nengah Suparta, M.Si, dean of Mathematics and Natural Science Faculty, Ganesha University of Education, for funding this research. The authors would also like to thank Mr. Prof. Ir. I Nyoman Arya Thanaya, $\mathrm{ME}, \mathrm{PhD}$., coordinator at the Doctor of Engineering Study Program, Udayana University, for his support to our research.

\section{Appendix}

\section{(1) Emotional questionnaire}

Q1Ep1 I Rajapala is one of the Balinese folk tales. If you have ever heard or known about the story of I Rajapala, how do you feel?

○ Very moved 
- Sad to live as a hunter

○ Don't know the story

- Happy as a hunter

○ Very happy to live freely in the forest

Q2Ep1 If you were I Rajapala, wouldn't you feel guilty about hiding the shawl belonging to the angel Ken Sulasih?

- Not feeling guilty

○ Don't feel guilty

- Not feeling guilty which is important to angels

$\circ$ Average Feeling guilty

$\circ$ Feeling guilty

Q3Ep1 If you were I Rajapala, wouldn't you feel sorry to see a woman cry because she lost her shawl?
- Feel sorry
○ Feel very sorry
○ Don't feel sorry
- Ordinary feel neutral
○ What do you feel sorry for?

Q4Ep1 If you were I Rajapala, wouldn't you feel annoyed when your arrows keep missing?

○ Yes, I feel annoyed

- Ordinary neutral

- Yes, I feel very upset that the animal escaped

- No, because there is still another chance

- No, because I'm sorry for the animals

Q5Ep1 If you were I Rajapala, would you still want to be a hunter?

$\circ$ Yes, because there is no other job

○ Yes, because hunting gets faster results

○ I don't know what to do

- No, because killing is a sinful act

○ No, because hunting means killing

Q1p2 I Durma in his childhood was very loved and guided by his mother, if you were I Durma how would you feel?

- Feel happy being loved
- Feel very annoyed not free

○ Don't know and get dizzy

○ Feel very happy to learn a lot

○ Feel annoyed by a lot of advice

Q2p2 If you were I Durma, how would you feel when your friends mock you when you were not careful in playing Tajog?

$\circ$ Feel very angry

- Complain

- Ordinary feel neutral

- Do not care.

○ Laugh

Q3p2 If you were I Durma, don't you feel annoyed when you always fail to answer questions on the first mission?

- Yes, I feel annoyed

- I feel neural

- Yes, I really annoyed at being wrong all the time

○ No, because it can still be repeated

- No, because you can learn to concentrate

Q4p2 If you are I Durma, would you feel happy if you could answer every little bit correctly and correctly?

○ Not happy

○ Very unhappy if I fail

$\circ$ Neutral

○ Very happy, especially all right

○ Happy means having knowledge

Q5p2 If you were I Durma, would you feel happy if you could answer every little bit correctly and correctly?

- Not happy

- Very unhappy if you fail

- Ordinary neutral

- Very happy, especially all right

○ Happy means having knowledge

\section{(2) Game-factor questionnaire}

Q1Ep1 In your opinion, is the purpose of this game play clear? 

- Very clear
- Clear
○ Do not know
- Not clear
○ Very unclear

Q2Ep1 Do you think the instructions and steps in this game are easy for you to understand?
○ Very easy
○ Easy
- Do not know
○ Difficult
- Very difficult

Q3Ep1 According to your opinion, do the operational and interaction processes of your easy games always miss?
- Very easy
○ Easy
- Do not know
- Difficult
- Very difficult

Q4Ep1 According to your opinion, can you play the game in various of ways?
- Yes, in a very varies ways
○ Yes, in varies ways
- I don't know
- Not various ways
○ Extremely difficult ways un varies ways

Q5Ep1 According to your opinion, is the storyline of this game easy for you to understand?
○ Very easy to understand
○ Easy to understand
○ Do not know
- Difficult to understand
- Very difficult to understand

Q1Ep2 According to your opinion, is the Tajog game is a challenging?
○ Very challenging

○ Challenging

- Ordinary

$\circ$ Not challenging

- Not very challenging

Q2Ep2 A track where tajog plays is varied according to the level of difficulty. How do you agree to this statement?

- Strongly agree

- Agree

○ Do not know

- Disagree

- Strongly disagree

Q3Ep2 game over occurs if you fail the mission you do, and you can repeat this mission. What is your opinion?

- Very good for accuracy

- A good strategy keeps time going

○ Do not know

- Not good for players

$\circ$ Time is running out fast for players

Q4Ep2 According to your opinion, can games be useful for eliminating stress?

○ Very useful

○ Could be useful

○ I don't know

○ Un useful

○ It is very difficult to be of use

Q5Ep2 Do you think the mission of this game is easy for you to understand?

○ Very easy to understand

○ Easy to understand

- Do not know

- Difficult to understand

- Very difficult to understand

\section{(3) Character questionnaire}

Q1Ep1 Hunting will inevitably lead to the killing of animals, do you think killing animals is a sinful act? 

○ Very sinful
○ Sinful
○ Don't know
- No sin
$\circ$ Very innocent

Q2Ep1 If you were I Rajapala, when you wanted to shoot an arrow a pig, suddenly there was a snake near you. What would you do in that situation?
$\circ$ Keep shooting the hog
- Avoid snakes
- Do not know
$\circ$ Let the pigs go
- Kill the snake

Q3Ep1 If you were I Rajapala, and you chased shot pigs and birds part many times, but never hit the target. What would you feel?
- Very desperate
- Do not give up
○ Don't know
○ Frustrated
- Enthusiastic

Q4Ep1 After hiding the scarf, I Rajapala approached Ken Sulasih who was confused looking for his lost scarf. What do you think should be done by I Rajapala?
- Immediately return his scarf
○ Keep it hidden
- Not return
- Return at a later date
○ I do not know what to do

Q5Ep1 There are 20 arrows available and 20 minutes for the 'easy' level. What did you do to complete the 'first' mission?
- Chase and aim at the hog.
- Shoot animals as often as possible.
$\circ$ Find the pigs and shoots them
- Don't know and confused

- Continue to chase until the animal is exhausted

Q1Ep2 I Durma as a child studied diligently about ethical values. What do you think?
○ Very good
○ Good
- Neutral
- Not good
- Not very good

Q2Ep2 According to your opinion, is it true that "Tri Kaya Parisuda" thinking, saying and behaving well a way of life that must be done to be a good person?
- Very true
○ Right
- Do not know
- Untrue
$\circ$ Very untrue

Q3Ep2 When playing with friends, some of I Durma's friends had opinions and behaviors that were incompatible with him. If you were I Durma, what would you think?

○ It is very natural that opinions are not the same

- It's a natural thing

- I do not care

- I want the same opinion

- I force all opinions to be the same

Q4Ep2 When learning from his mother, I Durma always asked a lot of questions until he understood. What do you think?

○ I strongly disagree with chatty people

- I disagree asking many questions

- I feel neural

- I agree in order to understand

- I strongly agree that all is understood

Q5Ep2 When playing with friends, I Durma didn't express he things that were not suitable what he behind and felt. What do you think?

○ Strong integrity

○ Integrity

○ It is common

○ Un integrity

○ Strong un integrity 


\section{References}

[1] A. F. Barbosa, P. N. Pereira, J. A. Dias, and F. G. Silva, "A new methodology of design and development of serious games," International Journal of Computer Games Technology, vol. 2014, article no. 8, 2014. https://doi.org/10. $1155 / 2014 / 817167$

[2] H. R. Marston, "Older adults as 21 st century game designers," The Computer Games Journal, vol. 1, pp. 90-102, 2012. https://doi.org/10.1007/BF03392330

[3] N. Sukajaya, K. E. Purnama, and M. H. Purnomo, "Intelligent classification of learner's cognitive domain using Bayes net, naïve Bayes, and J48 utilizing Bloom's taxonomy-based serious game," International Journal of Emerging Technologies in Learning (IJET), vol. 10, no. 2, pp. 46-52, 2015. https://doi.org/10.3991/ijet.v10i2.4451

[4] I. N. P. Suwindra, I. K. G. D. Putra, I. M. Sudarma, and N. P. Sastra, "Developing balinese culture-based serious game model: I Rajapala as a Hunter," in Proceedings of 2018 International Conference on Smart Green Technology in Electrical and Information Systems (ICSGTEIS), Bali, Indonesia, 2018, pp. 114-119. https://doi.org/10.1109/ICSGTEIS.2018.8709109

[5] F. Laamarti, M. Eid, and A. El Saddik, "An overview of serious games," International Journal of Computer Games Technology, vol. 2014, article no. 11, 2014. https: //doi.org/10.1155/2014/358152

[6] Q. Pan, "A interactive teaching mode based on educational games: case study of acupuncture course," International Journal of Emerging Technologies in Learning (IJET), vol. 14, no. 17, pp. 167-181, 2019. https://doi.org/10.3991/ijet. v14i17.11205

[7] P. S. Lengyel, "Can the game-based learning come? Virtual classroom in higher education of 21st century," International Journal of Emerging Technologies in Learning, vol. 15, no. 2, pp. 112-126, 2020. https://doi.org/10.3991/ ijet.v15i02.11521

[8] A. Mavridis, T. Tsiatsos, M. Chatzakis, K. Kitsikoudis, and E. Lazarou, "Gamified assessment supported by a dynamic 3D collaborative game," in Virtual Reality in Education: Breakthroughs in Research and Practice. Hershey, PA: IGI Global, 2019, pp. 399-412. https://doi.org/ 10.4018/978-1-5225-8179-6.ch020
[9] B. Cowley, J. L. Moutinho, C. Bateman, and A. Oliveira, "Learning principles and interaction design for 'Green My Place': a massively multiplayer serious game," Entertainment Computing, vol. 2, no. 2, pp. 103-113, 2011. https://doi.org/10.1016/j.entcom.2011.01.001

[10] P. Vate-U-Lan, "Transforming classrooms through gamebased learning: a feasibility study in a developing country," International Journal of Game-Based Learning (IJGBL), vol. 5, no. 1, pp. 46-57, 2015. https://doi.org/10.4018/ijgbl. 2015010104

[11] I. W. Suastra, B. Jatmiko, N. P. Ristiati, and L. P. B. Yasmini, "Developing characters based on local wisdom of Bali in teaching physics in senior high school," Jurnal Pendidikan IPA Indonesia, vol. 6, no. 2, pp. 306-312, 2017. https://doi.org/10.15294/jpii.v6i2.10681

[12] T. Lickona, Educating For Character. Jakarta, Indonesia: PT Bumi Bersama, 1991.

[13] T. Lickona, "Do parents make a difference in children's character development," 1998 [Online]. Available: https://www2.cortland.edu/dotAsset/4e26603a86bb-4c2a-b111-d590dc4e1dce.pdf

[14] E. Lotfi and M. R. Karimi, "OPEC oil price prediction using ANFIS," Journal of Mathematics and Computer Science, vol. 10, pp. 286-296, 2014.

[15] A. Y. Sonmez, S. Kale, R. C. Ozdemir, and A. E. Kadak, "An adaptive neuro-fuzzy inference system (ANFIS) to predict of cadmium $(\mathrm{Cd})$ concentrations in the Filyos River, Turkey," Turkish Journal of Fisheries and Aquatic Sciences, vol. 18, no. 12, pp. 1333-1343, 2018. https: //doi.org/10.4194/1303-2712-v18_12_01

[16] S. Winton, "Character education: implications for critical democracy," International Critical Childhood Policy Studies Journal, vol. 1, no. 1, pp. 42-63, 2008.

[17] Y. R. Shi and J. L. Shih, "Game factors and game-based learning design model," International Journal of Computer Games Technology, vol. 2015, article no. 11, 2015. https://doi.org/10.1155/2015/549684

[18] I. K. Kwon and S. Y. Lee, "An emotional space modeling for the adaptive emotional model design based on Sugeno fuzzy inference," International Journal of Software Engineering and Its Applications, vol. 8, no. 6, pp. 109-120, 2014. 
[19] C. Herodotou, M. Kambouri, and N. Winters, "The role of trait emotional intelligence in gamers' preferences for play and frequency of gaming," Computers in Human Behavior, vol. 27, no. 5, pp. 1815-1819, 2011. https://doi. org/10.1016/j.chb.2011.04.001

[20] L. Agung, "Character education integration in social studies learning," Historia: Jurnal Pendidik dan Peneliti Sejarah, vol. 12, no. 2, pp. 392-403, 2011.

[21] Zaheeruddin and Garima, "A neuro-fuzzy approach for prediction of human work efficiency in noisy environment," Applied Soft Computing, vol. 6, no. 3, pp. 283-294, 2006. https://doi.org/10.1016/j.asoc.2005.02.001

[22] M. A. Raharja, I. D. M. B. A. Darmawan, D. P. E. Nilakusumawati, and I. W. Supriana, "Analysis of membership function in implementation of adaptive neuro fuzzy inference system (ANFIS) method for inflation prediction," Journal of Physics: Conference Series, vol. 1722, article no. 012005, 2021. https://doi.org/10.1088/17426596/1722/1/012005

[23] G. G. Tiruneh, A. R. Fayek, and V. Sumati, "Neuro-fuzzy systems in construction engineering and management research," Automation in Construction, vol. 119, article no. 103348, 2020. https://doi.org/10.1016/j.autcon.2020. 103348

[24] U. Murad and M. Malkawi, "Artificial neuro fuzzy logic system for detecting human emotions," in Proceedings of 2012 International Conference on Computer, Information and Telecommunication Systems (CITS), Amman, Jordan, 2012, pp. 1-4. https://doi.org/10.1109/CITS.2012. 6220388

[25] D. Dicheva and C. Dichev, "Gamification in education: where are we in 2015?," in Proceedings of E-Learn: World Conference on E-learning in Corporate, Government, Healthcare, and Higher Education, Kona, HI, 2015, pp. 1445-1454.

[26] J. H. Bae, "Development of smart game based on multiplatform game engine," International Journal of Multimedia and Ubiquitous Engineering, vol. 11, no. 3, pp. 345350, 2016. https://doi.org/10.14257/ijmue.2016.11.3.32

[27] M. A. Zielke, M. J. Evans, F. Dufour, T. V. Christopher, J. K. Donahue, P. Johnson, E. B. Jennings, B. S. Friedman, P. L. Ounekeo, and R. Flores, "Serious games for immersive cultural training: creating a living world," IEEE Computer Graphics and Applications, vol. 29, no. 2, pp. 49-60, 2009. https://doi.org/10.1109/MCG.2009.30

[28] A. F. Barbosa and F. G. Silva, "Serious games: design and development of OxyBlood," in Proceedings of the 8th International Conference on Advances in Computer Entertainment Technology, Lisbon, Portugal, 2011, pp. 1-8. https://doi.org/10.1145/2071423.2071442

[29] MathWorks, "Fuzzy Logic Toolbox, MATLAB user guide," 2021 [Online]. Available: https://www.mathworks. com/help/fuzzy/

[30] R. Faisal, N. S. Surjandari, and S. Setiono, "Prediksi stabilitas lereng menggunakan adaptive neuro-fuzzy metode hybrid [Prediction of slope stability using adaptive neurofuzzy hybrid method]," Matriks Teknik Sipil, vol. 6, no. 3, pp. 439-450, 2018. https://doi.org/10.20961/mateksi.v6i3. 36549

[31] H. Fattahi, "Prediction of slope stability using adaptive neuro-fuzzy inference system based on clustering methods," Journal of Mining and Environment, vol. 8, no. 2, pp. 163-177, 2017. https://doi.org/10.22044/jme.2016.637

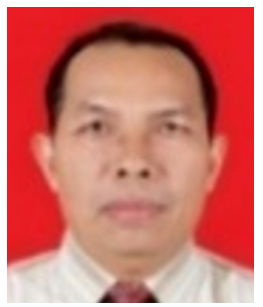

I Nyoman Putu Suwindra is a lecturer in Department of Physics Education, Faculty of Mathematics and Natural Sciences, Ganesha Education University, SingarajaIndonesia. He received bachelor's degree in Physics Education at Udayana University in 1984 and his master's degree in Computer Science at UGM in 2003. He is a doctor candidate at Doctor of Engineering Study Program, Udayana University, Bali. His research topic of interests is game development, artificial intelligence (AI), and e-learning.

E-mail: suwindra@undiksha.ac.id

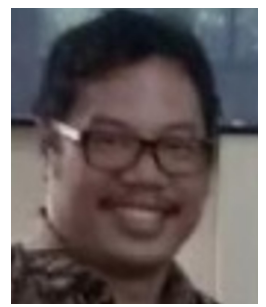

I Ketut Gede Darma Putra is a Professor at Department of Information Technology, Engineering Faculty, Udayana University, Denpasar-Indonesia. He received his bachelor's degree in Information Technology at ITS, in 1997, his master's degree in Information System and Computer Technology at UGM in 2000, and his doctoral degree in 2003. His research topic of interests is images processing, and data mining. 
E-mail: ikgdarmaputra@unud.ac.id

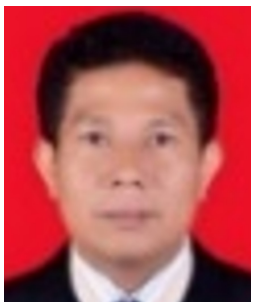

Made Sudarma is a Professor at Department of Electrical Engineering, Faculty of Engineering, Udayana University, Denpasar-Indonesia. He received his bachelor's degree in Electrical Engineering at ITS in 1992. His master's degree is in School of Information Technology and Engineering, Ottawa University, Canada in 2000. His doctoral degree was received in Ergonomics at Udayana University in 2012. His research interests is in human computer interaction (HCI) and decision support system.

Email: msudarma@unud.ac.id

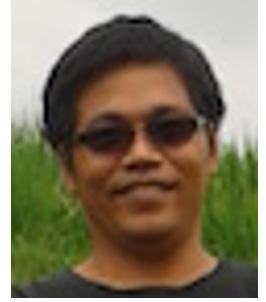

Nyoman Putra Sastra is a lecturer at Department of Electrical Engineering, Faculty of Engineering, Udayana University, Denpasar-Indonesia. He received his bachelor's degree in Electrical Engineering from ITB in 1998, and his master's degree in 2001. He received his Doctoral degree in Electrical Engineering from ITS in 2008. His current interest is wireless visual sensor network. Now he is a chairman of the Computer Center Unit of the Udayana University.

E-mail: putra.sastra@unud.ac.id 